\title{
Levantamento florístico do municipio de Pedra Preta-RN: subsídios para empreendimentos futuros
}

\author{
Floristic the municipality of Pedra Preta-RN: subsidies for future developments
}

\section{Diana Soares dos Santos'; Carlos Enrique de M. Jerônimo²}

\author{
'Bióloga pela Universidade Potiguar. Especialista em Gestão Ambiental e Recursos Hídricos. \\ ${ }^{2}$ Orientador. Engenheiro Químico (UFRN). Doutor em Engenharia de Processos e Ambiental.
}

\section{Resumo}

O município de Pedra Preta no estado do Rio Grande do Norte vem sendo alvo da pretensão de inúmeros empreendimentos, sobretudo, para geração de energia elétrica a partir de energia eólica. Entretanto, o referido município encontra-se no bioma Caatinga, região de grande importância e sensibilidade para a região nordeste. Neste trabalho procura-se situar geograficamente o espaço estudado, considerando não apenas os aspectos físicos regionais, mas realizando um levantamento semi-quantitativo dos elementos florísticos que constituem a zona de influência do referido município. Tais informações poderão ser utilizadas para comparativos de avaliação de aspectos/impactos e estimativas de cenários para licenciamento ambiental na referida região. As observações demonstram que situação da vegetação na área estudada é afetada pela ação antrópica. Porém, ainda é possível encontrar a vegetação natural de caatinga hiperxerófila, composta por suas espécies típicas. Como os impactos negativos para a vegetação gerados pela implantação de empreendimentos industriais, bem como para operação dos mesmos são mínimos e reversíveis, tais atividades não se mostram agressiva a vegetação de Caatinga.

Palavras Chave: Caatinga. Levantamento Florístico. Pedra Preta.

\begin{abstract}
The town of Pedra Preta in the state of Rio Grande do Norte has been the target of numerous claims of enterprises, especially for electric power generation from wind energy. However, the said council is in the Caatinga region of great importance and sensitivity for the northeast region. This paper seeks to situate geographically the area studied, considering not only the physical aspects of regional, but performing a semi-quantitative survey of floristic elements that constitute the zone of influence of the said municipality. Such information could be used for comparative evaluation of aspects / impacts and estimates of scenarios for environmental license in that region. The observations show that the situation of the vegetation in the study area is affected by human action. However, you can still find the natural vegetation of Caatinga of hiperxerófila, composed of its typical species. As the negative impacts to vegetation generated by the implementation of industrial enterprises as well as for the same operation are minimal and reversible, such activities do not show aggressive vegetation of the Caatinga.
\end{abstract}

Keywords: Caatinga. Floristic. Pedra Preta. 


\section{INTRODUÇÃO}

O bioma caatinga, inserido no domínio do semi-árido, representa, segundo Rodal; Nascimento (2002) apud Heywood (1997), um importante centro de biodiversidade da América. Esse domínio ocupa uma área de $788.064 \mathrm{~km}^{2}$, equivalente a $48 \%$ da região Nordeste - sensu IBGE (2010) e abriga, além da vegetação caducifólia espinhosa (VCE), a caatinga propriamente dita, outras formações vegetacionais com fisionomia e flora diferenciadas, como as florestas, e cerrados situados nos enclaves úmidos e subúmidos, totalizando $42.855,9 \mathrm{~km}^{2}$, e extensas faixas ecotonais com o cerrado e a floresta atlântica (Souza et al., 1994). Essas áreas vêm sendo vislumbradas por inúmeros empreendimentos para uso na construção de empreendimentos tais como: usinas de geração de energia elétrica através de aerogeradores, indústrias cimenteiras, beneficiamento de cal hidratado etc.

Entretanto, Lacerda et al (2005), cita que ao lado das evidências de sua importância, a cobertura vegetal presente nas áreas ciliares da região onde está inserida a caatinga vem sendo crescentemente degradada, independente do seu potencial ou empreendimentos futuros. Mueller (1998) afirma que a generalizada destruição ou degradação das matas ciliares vem contribuindo para intensificar a erosão dos solos, a destruição da vida silvestre, o desfiguramento da paisagem à beira dos rios, e principalmente, o assoreamento e a degradação de rios, lagos e barragens. Nesse sentido, estas matas são alvo freqüente dos impactos negativos causados pelo homem nas bacias hidrográficas devido, sobretudo, ao fato de que estas áreas contêm os solos mais férteis de uma bacia, o que torna estas florestas mais propensas a serem derrubadas para fins agrícolas (van den Berg \& Oliveira-Filho 2000).

Conseqüentemente, as bacias hidrográficas do semi-árido enfrentam forte pressão sobre os recursos disponíveis em áreas como as de matas ciliares, consideradas estas como ambientes de exceção por absorver alterado padrão fisionômico e florístico da caatinga que recobrem as margens aluviais dos rios intermitentes e permanentes que cortam o semiárido. Causando diversos impactos sócio-ambientais a referida região.

O município de Pedra Preta no estado do Rio Grande do Norte é uma dessas áreas. Hoje fortemente pretendida para instalação de empreendimentos de geração de energia elétrica-eólica, tende a suprimir zonas significativas desse bioma, causando danos que não se tem base estatística ou projeções seguras para o seu desenvolvimento.
No município encontra-se em sua totalidade a vegetação da Caatinga. Trata-se de um Bioma cujos limites estão restritamente inseridos no território nacional, sendo assim um bioma exclusivamente brasileiro. A Caatinga é geralmente composta por um mosaico de tipos de vegetação geralmente caducifólia, xerófila e espinhosa, dependendo do mosaico de solos e disponibilidade hídrica (Amazonas et al., 2002). A vegetação de tal bioma ainda pode ser classificada como hipoxerófila e hiperxerófila, apresentando algumas alterações quanto ao tipo de vegetação podendo ser denominada de grameal, vegetação com carnaúba e vegetação mista de caatinga, cerrado e/ ou florestas.

A palavra caatinga, na língua indígena, significa "mata branca" ou "floresta branca". Tal denominação é devido ao fato de que a maioria das plantas perde as folhas na estação seca e muitas têm a casca clara ou reluzente, que juntamente com reflexo dos raios solares nessas estruturas proporcionam um aspecto branco ou prateado.

A vegetação desse bioma apresenta uma grande capacidade de regeneração. Existem duas estações distintas durante o ano: estação chuvosa (chamada inverno) e a época seca (chamada verão) de maior duração (Maia, 2012). Durante a época seca as espécies vegetais fazem jus à denominação do bioma, apresentam-se desprovidas de folhas com aspecto esbranquiçado, entretanto, na primeira chuva as atividades vitais logo são recuperadas e plantas enfolham-se rapidamente, modificado o cenário antes encontrado. As plantas e os animais ao longo da evolução desenvolveram estruturas e condições que os permitiram a adaptação às condições adversas proporcionadas pelo clima e solo deste bioma.

Devido à grande utilização de sua vegetação e exploração de terras para fins de monoculturas e atividade da pecuária é cada vez mais difícil encontrar uma área com o ecossistema original virgem, que nunca tenha sofrido intervenção humana ou de animais domésticos (Jerônimo; Santiago, 2012). Fato que não é diferente no referido município.

A Caatinga Hipoxerófila é uma formação fitoecológica que apresenta árvores e arbustos com espinhos, mas possui aspecto menos agressivo do que a Caatinga Hiperxerófila. Apresenta os três estratos herbáceo, arbustivo e arbóreo. O estrato herbáceo é composto principalmente por bromélias e gramíneas, e é geralmente composto por terófitas e geófitas. O estrato arbustivo, com vegetais de cerca de dois metros de altura, é constituído por principalmente por leguminosas, euforbiáceas, crótons e rubiáceas. $\mathrm{O}$ estrato arbóreo, com árvores 
de até quinze metros, podendo ser composto por anacardiáceas, leguminosas, cactáceas e várias outras.

A Caatinga Hiperxerófila apresenta uma vegetação de porte mais baixo que na caatinga hipoxerófila, ocorrendo, dentre outras, leguminosas, solanáceas, bignoniáceas, cactáceas e euforbiáceas. A presença de espécies com xeromorfismo é mais intensa e a densidade da vegetação é menor, constituindo uma vegetação mais espaçada.

De modo geral, a região é marcada por desmatamento devido a atividades agrícolas que sustentam a economia local. Segundo o IDEMA (2008) e Silva; Jerônimo (2012) os solos da área são utilizados para cultivo de algodão, milho, feijão, mandioca e algumas culturas de gergelim em pequenas áreas. Além disso, segundo a mesma fonte, caprinos e bovinos são criados com pastagem natural de forma mais extensiva na região. Tais atividades econômicas contribuem para o aumento do desmatamento e compactação do solo, o que causa impactos negativos significativos na vegetação de caatinga.

Neste trabalho procura-se situar geograficamente o espaço estudado, considerando não apenas os aspectos físicos regionais, mas realizando um levantamento semi-quantitativo dos elementos florísticos que constituem a zona de influência do referido município. Tais informações poderão ser utilizadas para comparativos de avaliação de aspectos/impactos e estimativas de cenários para licenciamento ambiental na referida região.

\section{METODOLOGIA}

O objeto empírico deste trabalho de pesquisa está direcionado para o levantamento florísticos de áreas do município de Pedra Preta, com potencial para exploração comercial ou industrial, sobretudo para empreendimentos de energia eólica, e deverá ser analisado quanto a dinâmica do território.

Adotou-se, no decorrer da pesquisa, instrumentos e procedimentos que forneceram subsídios para concretização desses objetivos. Os instrumentos ou técnicas utilizadas na pesquisa foram: a observação sistematizada por listas de verificação, individual ou em equipe, entrevistas, levantamento de referências e fontes pertinentes á área de estudo, organização e análise dos dados para aquisição das informações relacionadas ao tema proposto. Para contribuir com o estudo e enfatizar esta questão, adotou-se como metodo- logia, uma revisão bibliográfica, incluindo nesta, artigos, textos, materiais coletados na internet, estudo da legislação, estudos de outros autores e visita ao campo.

As atividades de campo foram executadas durante os meses de agosto a outubro de 2012, por uma equipe multidisciplinar. A área escolhida para o levantamento está localizada no município de Pedra Preta, sob as coordenadas 24M 820884.05m E/ $9387841.31 \mathrm{~m} \mathrm{~S}$. Inserida na mesorregião Central Potiguar e na microrregião Angicos, Pedra Preta limita-se ao norte, sul e oeste com Lajes e a leste com Jardim de Angicos.

Primeiramente, três áreas foram delimitadas para melhor caracterização da área e melhor entendimento de possíveis efeitos e impactos gerados pelo empreendimento. Assim, as três divisões consistem em: Área Diretamente Afetada (ADA), a qual consiste na área onde poderão ser instalados empreendimentos; Área de Influência Direta (AID), a qual compreende uma faixa de 600m que circundam as delimitações da ADA; e a Área de Influência Indireta (AII), a qual compreende o município em que a área de construção do empreendimento está inserida.

O estudo da biocenose presente na área foi realizado com o objetivo de identificar o bioma pertencente ao local do empreendimento, bem como a caracterização e a análise da relação das espécies vegetais encontradas com todo ecossistema pertinente às ADA, AID e AII. Dessa forma, foi possível averiguar a importância ecológica, econômica e social das espécies envolvidas e avaliar os possíveis impactos intrínsecos à construção de empreendimentos na citada região

Considerando uma sondagem através de fotografias aéreas foi realizada tanto para caracterização geral da área, como para elaboração de estratégia de ação para amostragem e identificação de espécimes vegetais nas ADA, AID e AII. Em seguida, tal amostragem qualitativa das espécies vegetais foi realizada direcionando-se uma equipe ao local em outubro de 2012 para analisar e identificar as espécies vegetais presentes. As espécies botânicas bem como as condições da vegetação encontradas foram registradas por fotografia para serem utilizadas no presente relatório a cargo ilustrativo. Os indivíduos mais representativos foram classificados em nível de espécie ou gênero e família.

A Área de Influência Indireta (AII) compreende o município de Pedra Preta que, de acordo com o IDEMA (2011), apresenta tanto vegetação caracterizada por Caatinga Hipoxerófila quanto 
Caatinga Hiperxerófila.

As coletas da vegetação arbustivo-arbórea nas áreas ciliares foram realizadas e processaram-se por caminhadas aleatórias e em intervalos que variaram de acordo com as equipes e visitas. Assim, a amostragem foi realizada por caminhamento, método expedito para levantamentos florísticos qualitativos. Para o estudo florístico foram anotadas a presença de todas as espécies arbóreas e arbustivas que ocorreram nas áreas. As espécies foram organizadas por família no sistema de Cronquist (1981), incluindo-se informação sobre o hábito. A definição dos nomes populares está de acordo com o conhecimento local.

\section{Caracterização do Município}

Pedra Preta, município no estado do Rio Grande do Norte (Brasil), localizado na microrregião de Angicos. De acordo com o censo realizado pelo IBGE (Instituto Brasileiro de Geografia e Estatística) no ano 2000, sua população é de 2.847 habitantes. Área territorial de $276 \mathrm{~km}^{2}$. Foi criado em 1963. Desde o dia 04/12/2010, o município vem sendo atingido por diversos abalos sísmicos. O maior deles até agora foi de magnitude 3,0 na Escala Richter.

\section{ANÁLISE E DISCUSSÃO DOS RESULTA- DOS}

A Área de Influência Direta compreendida no presente estudo, consiste numa faixa com $600 \mathrm{~m}$ de extensão contada a partir dos limites de fronteira da ADA. Tal área é marcada pela presença de loteamentos privados onde se podem encontrar sítios, além da abertura de vias locais para tráfego de veículos e trilhas. Tais atividades antrópicas impactam a vegetação natural local por causarem o denominado Efeito de Borda, o que aumenta principalmente o estresse hídrico na localidade, provocando diminuição da biodiversidade.

Devido à ação antrópica na região, foi possível encontrar algumas espécies exóticas na AID, como a Algaroba (Prosopis juliflora (Sw.) DC.) e Aveloz (Euphorbia tirucalli L.). O velame (Croton campestris A. St. - Hil) é outra espécie presente no levantamento.

Ainda assim, há algumas áreas na AID que se encontra com vegetação característica de caatinga hiperxerófila e com relativa densidade. Ainda que a vegetação tenha sido observada praticamente ausente de folhas devido ao período de estiagem, foi possível identificar algumas espécies nativas como a Catingueira (Poincianella pyramidalis (Tul.) L.P.

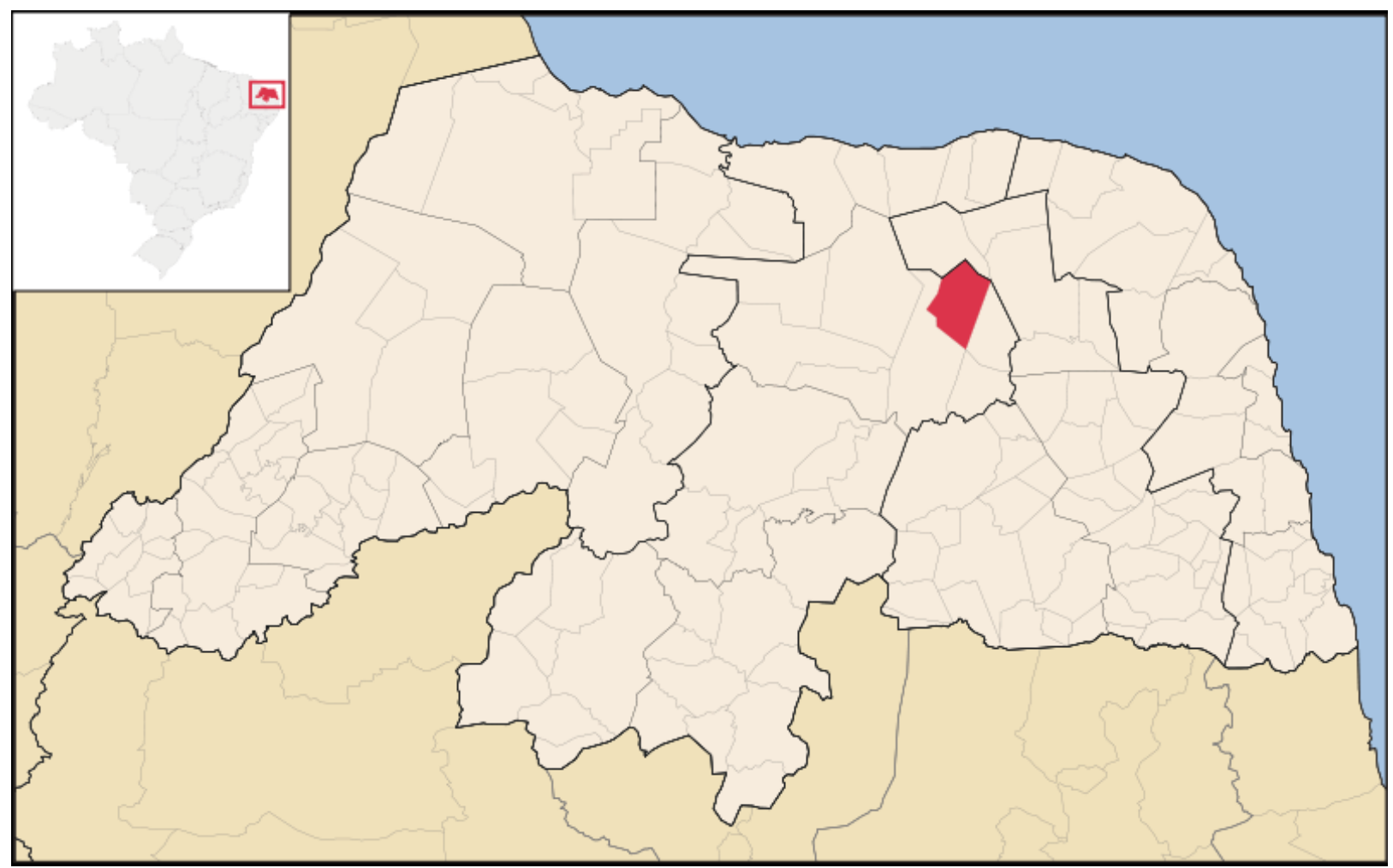

Figura 1. Mapa de localização do município de Pedra Preta/RN. 


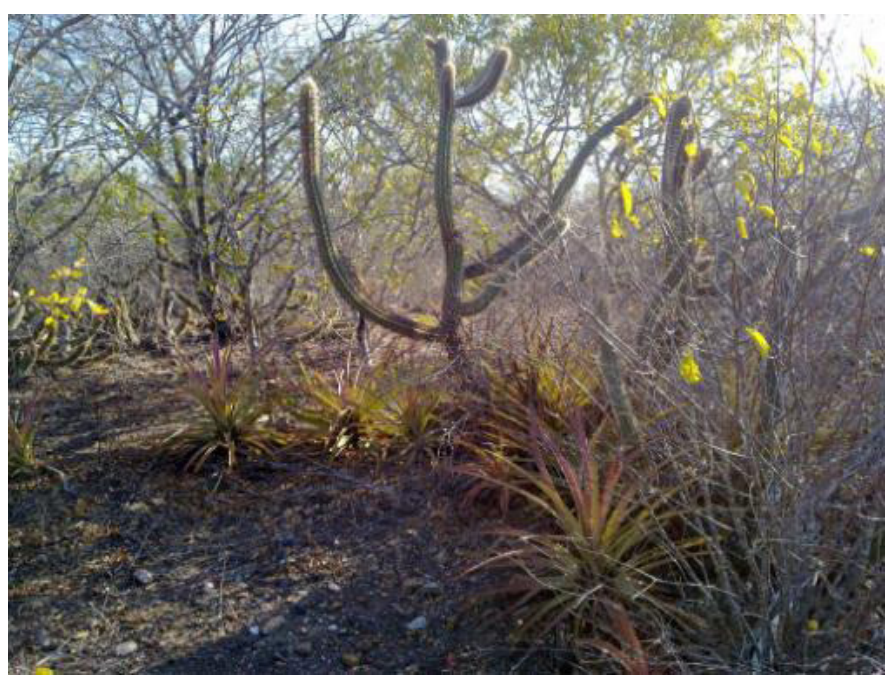

Figura 2. Broméliáceas e Cactáceas compondo a vegetação típica do bioma.

Queiroz), a Imburana (Commiphora leptophloeos (Mart.) J.B. Gillett) e Jurema (Mimosa sp.).

A jurema-preta (Mimosa tenuiflora (Willd. Poir.) tem um grande potencial como planta regeneradora de solos erodidos. É uma espécie indicadora de uma sucessão secundária progressiva ou de recuperação e sua tendência ao longo do processo é de redução da densidade (Maia, 2012).

Em decorrência da pouca disponibilidade hídrica há plantas que desenvolveram mecanismos para retenção de água, essas plantas compõem a família botânica Cactaceae. $\mathrm{Na}$ área há presença de cactáceas, notavelmente o cacto mandacaru (Cereus jamacaru DC) e do Facheiro (Pilosocereus pachycladus Ritter), que atinge até $10 \mathrm{~m}$ de altura e ocorre em toda região semi-árida nordestina, bem como do Melocactus zehntneri (Britton \&. Rose) Luetzelburg. (coroa-de-frade) e Pilosocereus sp.(xique-xique). $\mathrm{Na}$ área há também bastante ocorrência da bromeliácea Bromelia laciniosa Mart. Ex Schult vulgarmente conhecida como macambira, por entre os arbustos e árvores, que é popularmente conhecida por ser utilizada como alimento para o gado. Alguns desses exemplos são apresentados nas Figuras 2.

A área de estudada é composta por vegetação mais espaçada, tornando-se mais denso na região nordeste. Além disso, devido à área apresentar um reservatório artificial de água (açude) na região norte e outro a sudeste (Figura 3), a

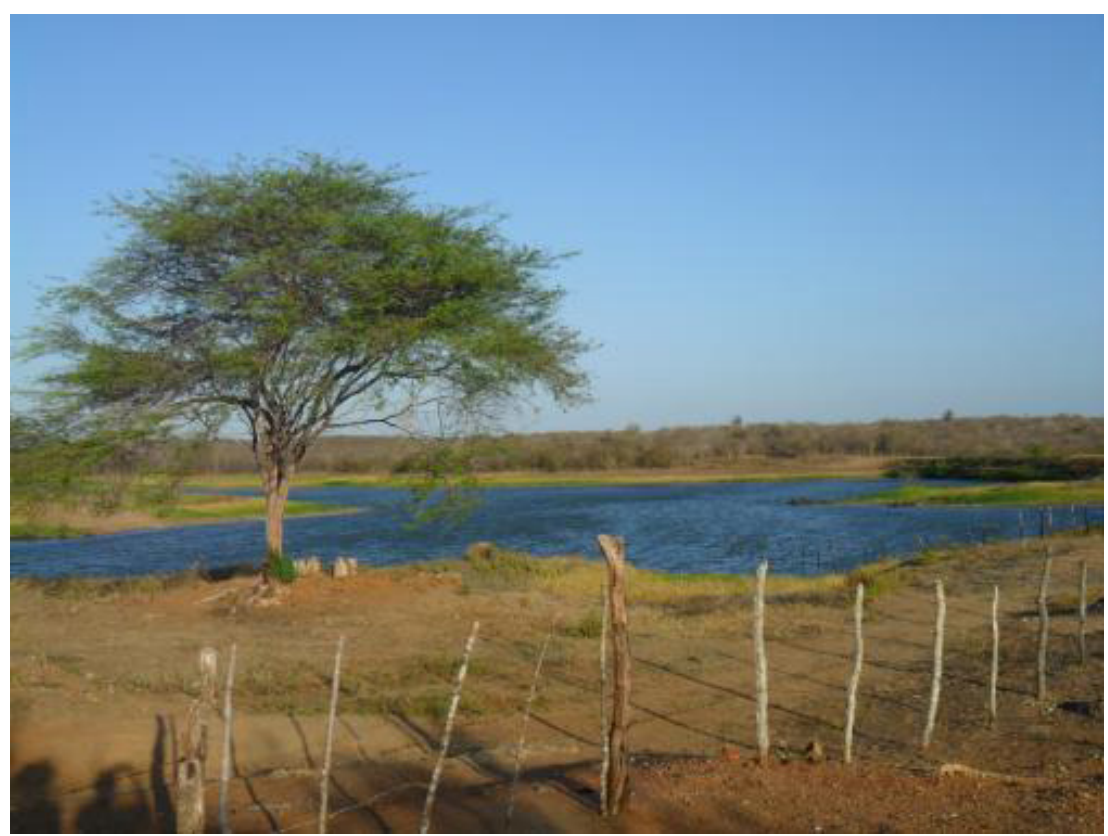

Figura 3. Açude na porção sul da área. Algaroba à esquerda. 


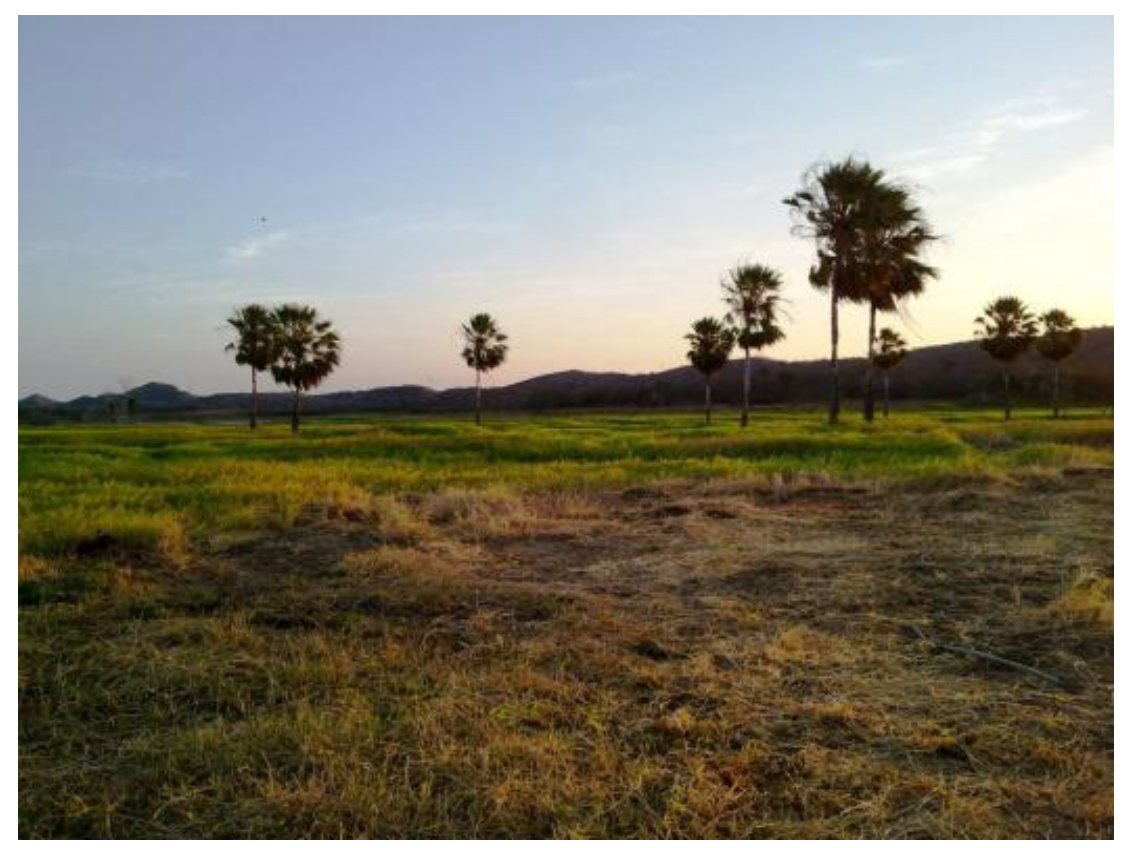

Figura 4. Carnaúbas (Copernicia prunifera (Mill.) H.E.Moore) presentes na região de estudo

vegetação nesses locais em específico apresenta configuração herbácea, com presença de gramíneas, Carnaúbas (Copernicia prunifera (Mill.) H.E.Moore (Figura 4) e coqueiros (Cocos nucifera L. - Figura 5). A presença de espécimes vegetais pioneiras como o Velame (Croton campestris A. St.-Hil) e espécies exóticas como a Algaroba (Prosopis juliflora (Sw.) DC.) e o Aveloz (Euphorbia tirucalli L.) são indicadores de ação antrópica principalmente marcada pela extração de lenha e pastagem livre de gado. Ainda assim, a vegetação natural é marcada pela predominância de um estrato arbustivo-arbóreo (Figura 6).

As espécies arbóreas típicas da caatinga são representadas pela Catingueira (Poincianella pyramidalis (Tul.) L.P. Queiroz), Jurema-preta (Mimosa tenuiflora (Willd.) Poir.), pelo Juazeiro (Ziziphus joazeiro Mart.), além das cactáceas como o Mandacaru (Cereus jamacaru DC), o Facheiro (Pilosocereus pachycladus Ritter - Figura 7). Outras cactáceas pertencentes ao estrato herbáceo e arbustivo como o Xique-xique (Pilosocereus sp.), a

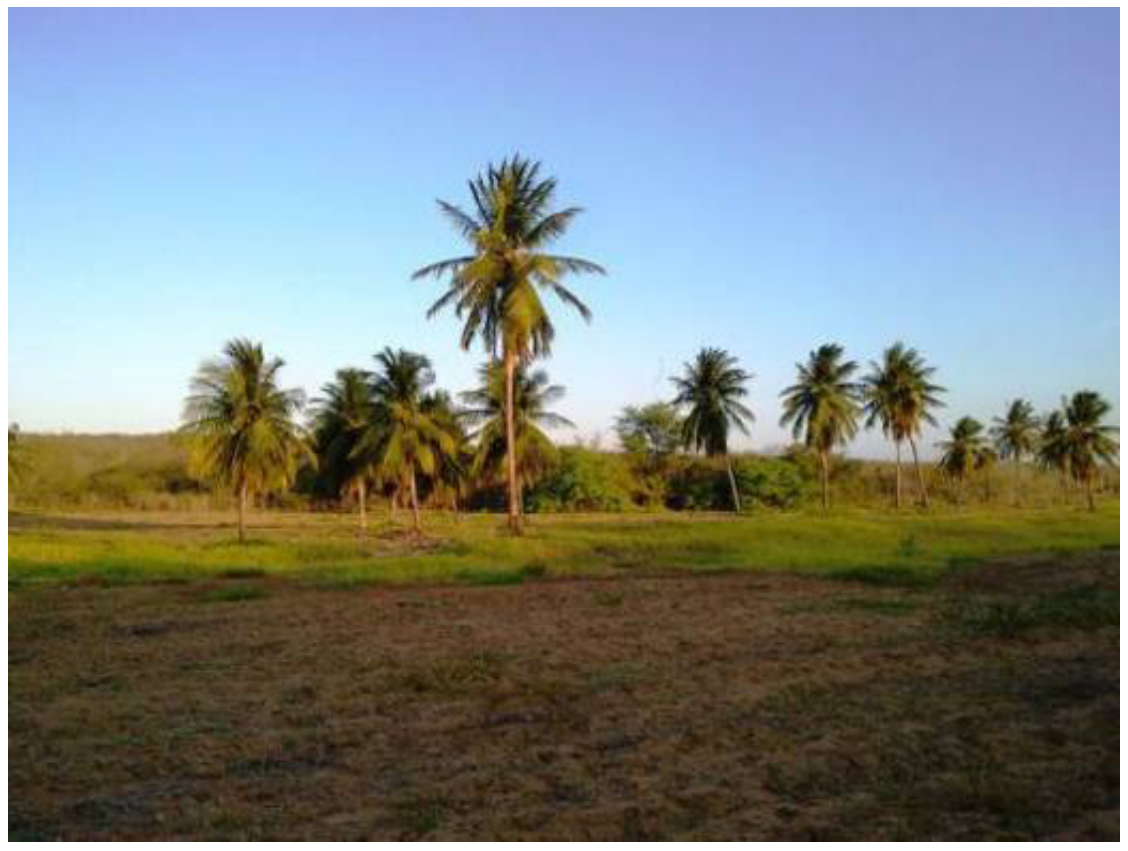

Figura 5. Coqueiros (Cocos nucifera L.) presentes na região de estudo. 


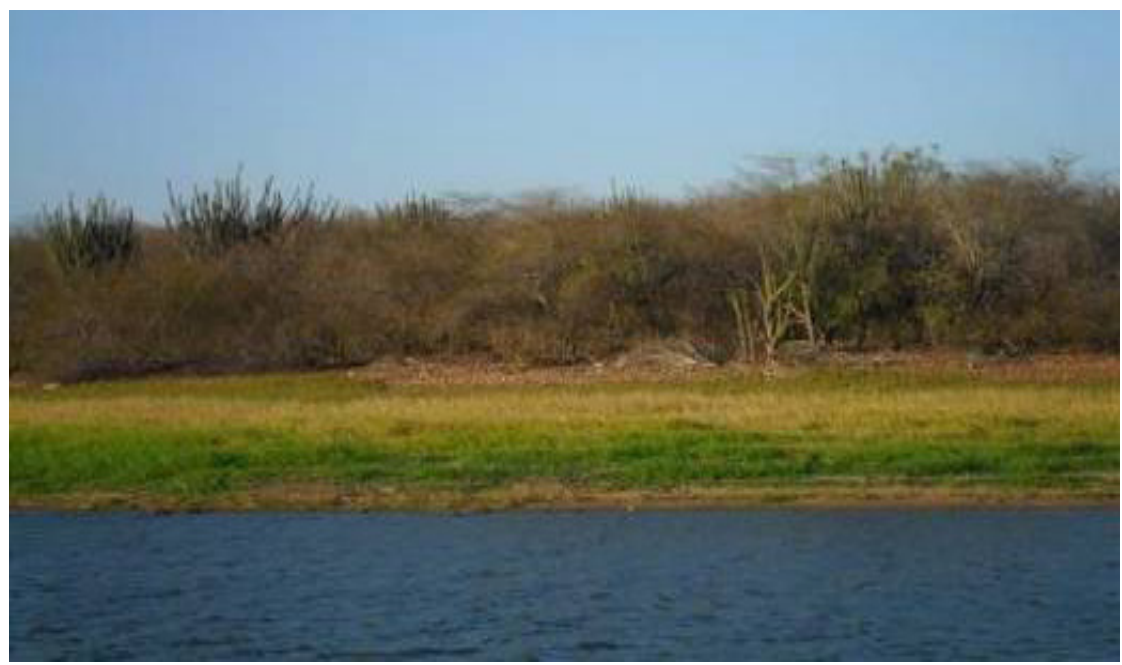

Figura 6. Vegetação arbustivo-arbórea próxima ao açude.

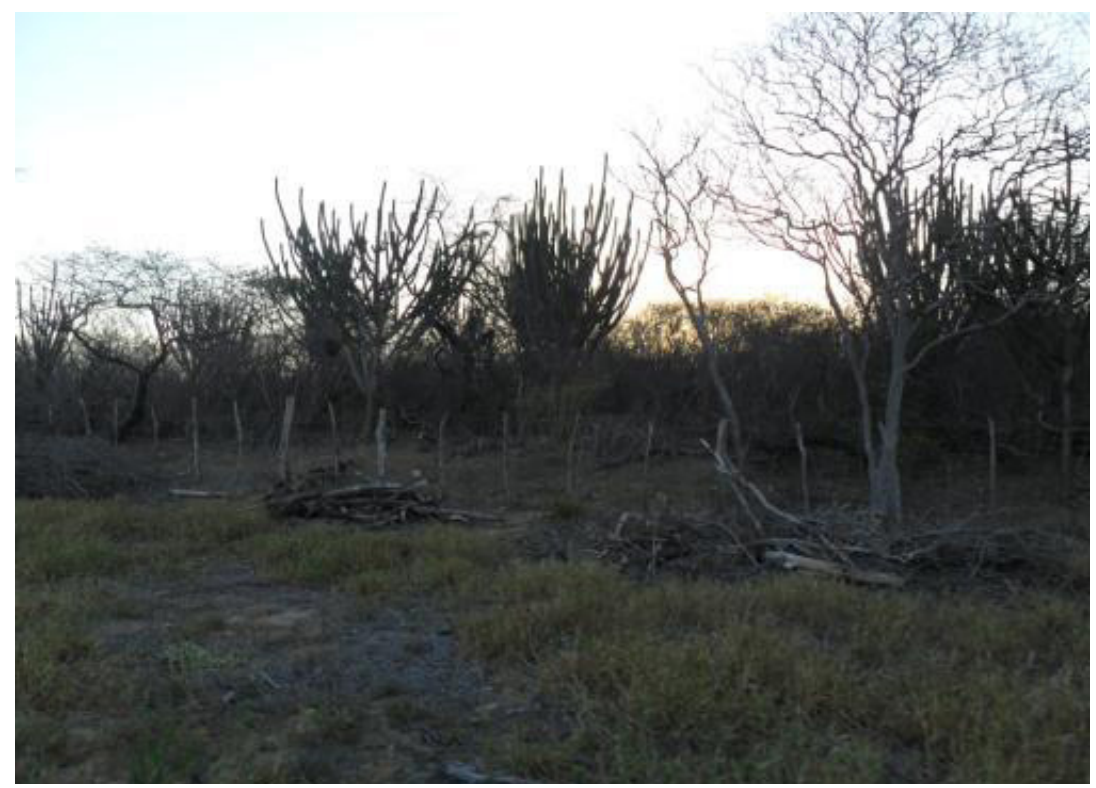

Figura 7. Presença do facheiro (Pilosocereus pachycladus Ritter)

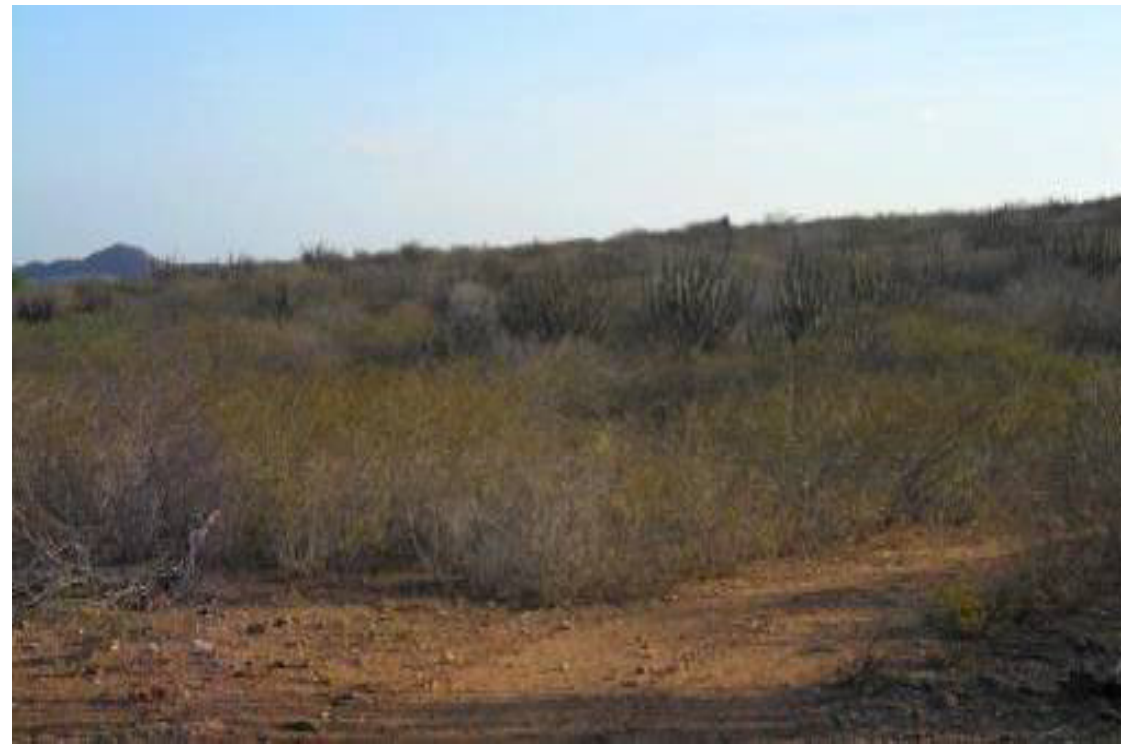

Figura 8. Estrato arbustivo com muita presença de cactáceas. 


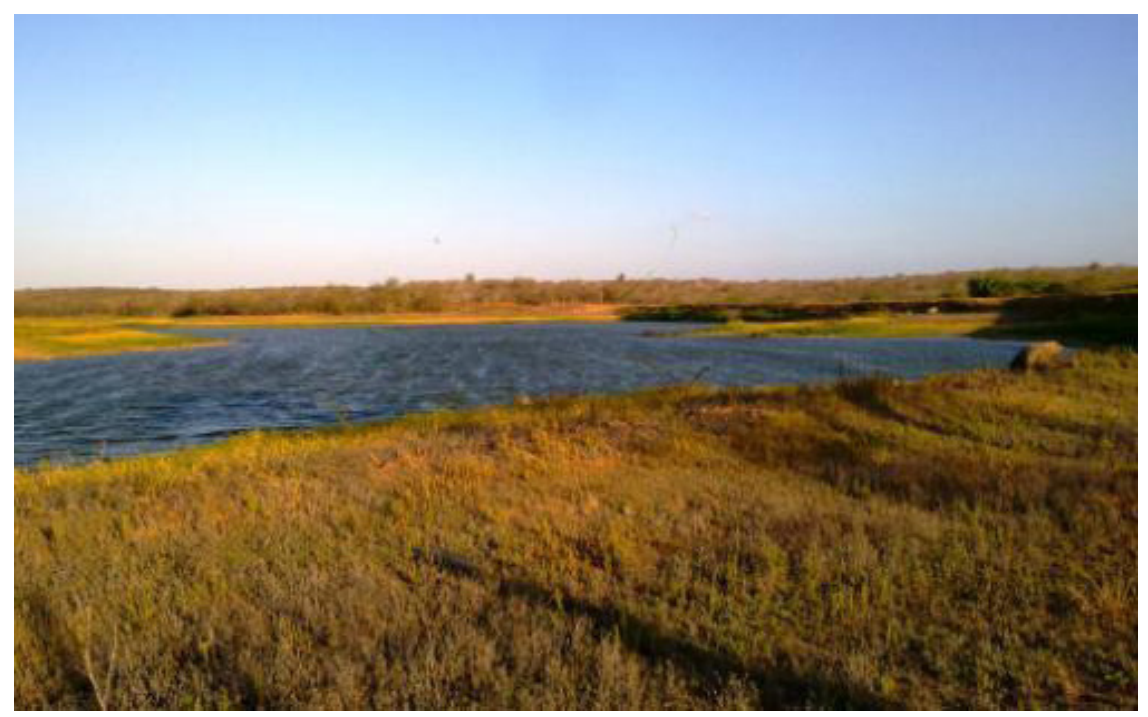

Figura 9. Localizado a sudoeste da região estudada.

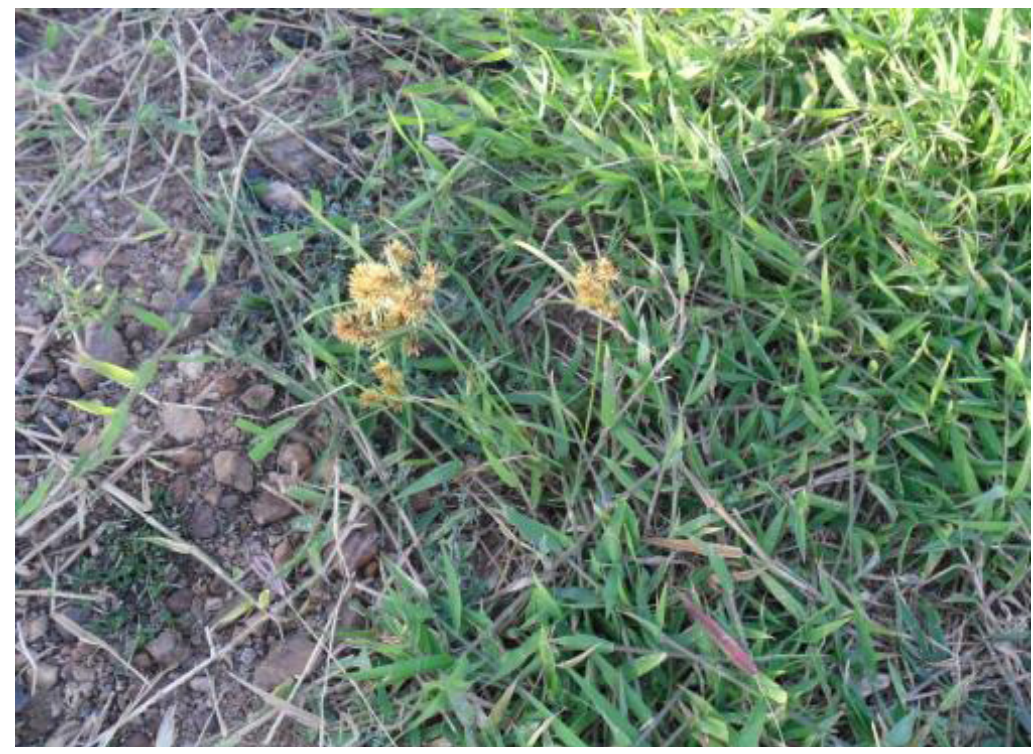

Figura 10. Ciperácea compondo vegetação herbácea

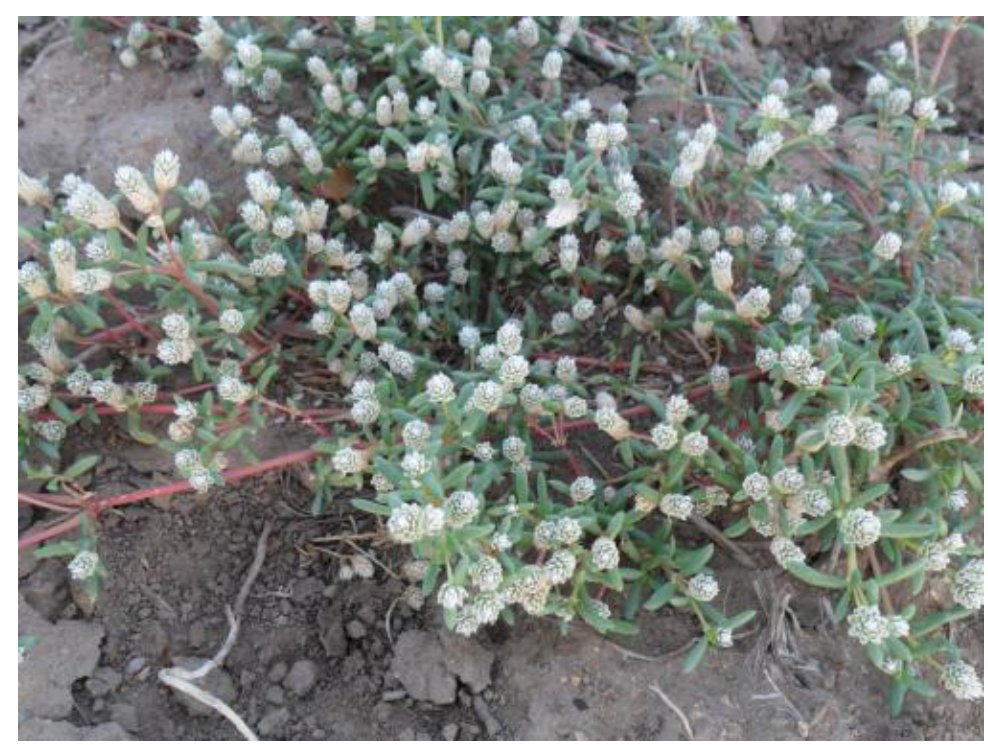

Figura 11. Bredinho (Blutaparon portulacoides (A. St-Hil) Mears). 


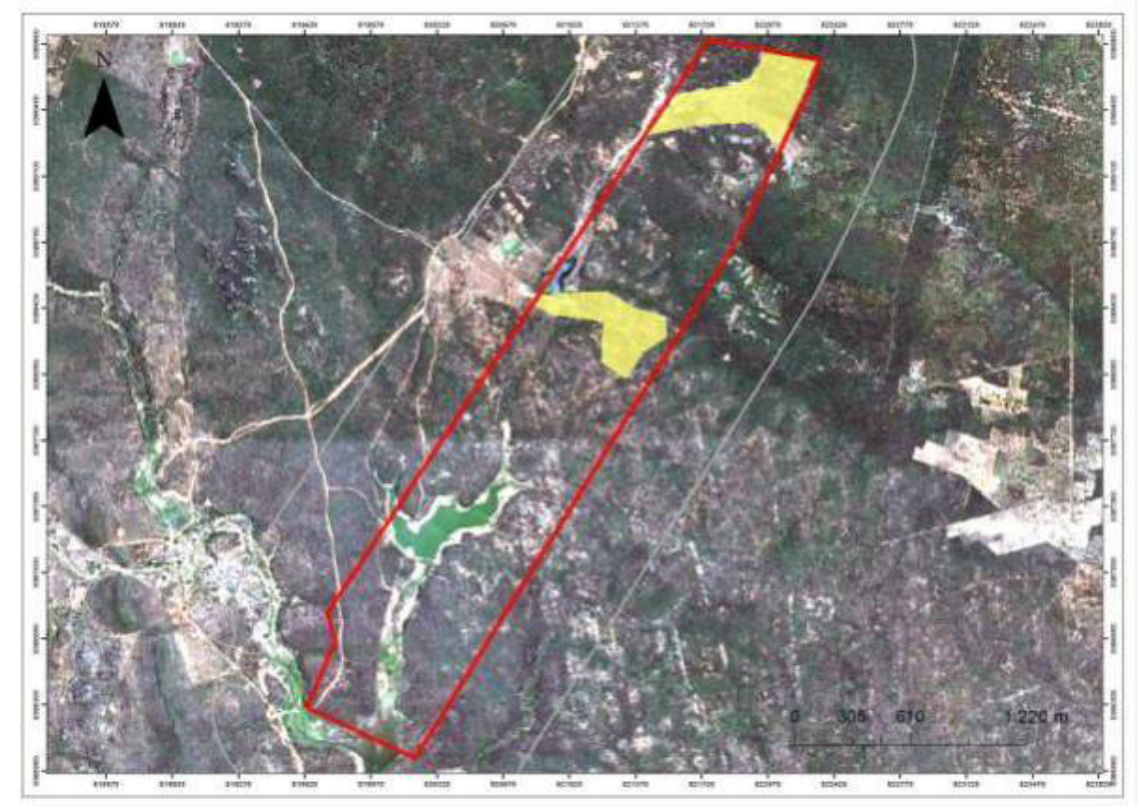

Figura 12. Imagem da aérea considerada no levantamento.

Coroa-de-frade (Melocactus zehntneri (Britton \&. Rose) Luetzelburg) e a Palma (Tacinga inamoena (K.Schum.)) também são bem representativos na área, uma vez que apresentam adaptação ao clima semi-árido como a retenção de água nos tecidos e a abertura dos estômatos (células diferenciadas) para trocas gasosas a noite.

No estrato arbustivo-herbáceo além de serem representados pelas cactáceas (Figura 8) já citadas, foi possível encontrar também a Macambira (Bromelia laciniosa), sendo popularmente conhecida por ser utilizada como alimento para o gado.

Conforme dito anteriormente nas adjacências dos açudes há uma vegetação herbácea composta principalmente por gramíneas (Figura 9) e ciperáceas, sendo essa última comum em solos alagáveis crista-de-galo (Heliotropium SP.), bredinho (Blutaparon portulacoides (A. St-Hil) Mears- Figura9).

A Figura 12 com a imagem aérea da delimitação da área (destacado em amarelo) onde a vegetação se apresenta mais alterada, possuindo em sua constituição a predominância do porte arbustivo-herbáceo. Há uma parte da gleba que se apresenta com vegetação densa composta por arbustos com espécimes arbóreos, esta, apresentando uma coloração verde escura dentro dos limites em vermelho; e outras com uma vegetação menos densa.

\section{CONCLUSÃO}

Tendo em vista, o levantamento que foi exposto, as observações feitas pertinentes a situação da vegetação na área estudada, foi possível concluir que a área é caracterizada pela ação antrópica. Porém, ainda é possível encontrar a vegetação natural de caatinga hiperxerófila, composta por suas espécies típicas. Como os impactos negativos para a vegetação gerados pela implantação de empreendimentos industriais, bem como para operação dos mesmos são mínimos e reversíveis, tais atividades não se mostram agressiva a vegetação de Caatinga.

Não há Reserva Legal averbada na propriedade na qual está inserido o proposto Parque Eólico. Entretanto, uma vez viabilizado o empreendimento a empresa proprietária do parque irá auxiliar o dono da matrícula na averbação de sua reserva, conforme Novo Código Florestal, Lei ${ }^{\circ}$ 12.651/12 em seu art $^{\circ} 12$.

A respeito da existência de Áreas de Proteção Permanente (APP), foram identificadas sua existência às margens de reservatórios artificiais (açudes) e cursos d'águas superficiais (drenagens), como pode ser observada no mapa de Restrições de Ocupação, que segue. Sua delimitação deu-se conforme definição também do Novo Código Florestal, em seu $\operatorname{art}^{\circ} 4$, a saber:

I - as faixas marginais de qualquer curso d'água natural, desde a borda da calha do leito regular, em largura mínima de: 
a) 30 (trinta) metros, para os cursos d'água de menos de 10 (dez) metros de largura; $\S 2^{\circ}$ No entorno dos reservatórios artificiais situados em áreas rurais com até 20 (vinte) hectares de superfície, a área de preservação permanente terá, no mínimo, 15 (quinze) metros.

\section{REFERÊNCIAS}

AMAZONAS, N. et al. levantamento florístico das angiospermas em um remanescente de floresta atlântica estacional na microbacia hidrográfica do rio Timbó, João Pessoa, Paraíba. Revista Nordestina de Biologia, 2012.

BRASIL. Constituição (1988). Constituição da República Federativa do Brasil. Brasilia, DF, Senado, 1988.

CRONQUIST, A. An integrated system of classification of flowering plants. Columbia University Press, New York. 1981.

FREIRE, M. S. B. Levantamento Florístico do Parque Estadual das Dunas do Natal. Acta bot. Brás. 4(2): 1990.

HEYWOOD, V. H. Centres of plant diversity. WWF/IUCN, London. 1997.

IBGE. INSTITUTO BRASILEIRO DE GEOGRAFIA E ESTATÍSTICA. Biblioteca - Pedra Preta-RN (Censo 2010). Disponível em: www.biblioteca.ibge. gov.br. Acesso em 17 de outubro de 2012.

IDEMA. INSTITUTO DE DESENVOLVIMENTO ECONÔMICO E MEIO AMBIENTE. Perfil do seu Município - Pedra Preta-RN. Natal: 2008. Disponível em: www.idema.rn.gov.br. Acesso em 17 de outubro de 2012.

JERONIMO, C. E. M.; SANTIAGO JR, A. F. desafios da administração ambiental publica: estudo de caso do município de Espírito Santo/RN. Revista de Administração de Roraima. Ed. 2. Vol. 1. p. 136-146. 2012.

LACERDA, A. V. et al. Levantamento florístico do componente arbustivo-arbóreo da vegetação ciliar na bacia do rio Taperoá, PB, Brasil. Acta bot. bras. 19(3): 647-656. 2005.
LIMA, J. L. S. de. Plantas forrageiras das caatingas: usos e potencialidades. Petrolina: EMBRAPA-CPATSA, 1996. 43.

MAIA, Gerda Nickel. Caatinga: árvores e arbustos e suas utilidades. São Paulo: D\&Z Computação Gráfica e Editora, 2012.

MUELLER, C.C. Gestão de matas ciliares. Pp. 185214. In: I.V. Lopes (org.). Gestão Ambiental no Brasil: experiência e sucesso. Rio de Janeiro, Editora Fundação Getúlio Vargas. 1998.

RODAL, M. J. N.; NASCIMENTO, L. M. Levantamento florístico da floresta serrana da reserva biológica de serra negra, microrregião de Itaparica, Pernambuco, Brasil. Acta bot. bras. 16(4): 481-500, 2002.

SANCHEZ, L. E. Avaliação de Impacto Ambiental: conceitos e métodos. Oficina de Textos. São Paulo, 2008.

SILVA, S. A.; JERÔNIMO, C. E. M. Educação ambiental, uma questão de "sobrevivência": estudo de caso para o município de Bom Jesus/RN. REMOA. v(9), n 9, p. 1992 - 2009, 2012.

SOUZA, M. et al. Redimensionamento da região semi-árida do Nordeste do Brasil. In: Conferência Nacional e Seminário Latino-Americano de Desertificação. Fundação Esquel do Brasil, Fortaleza. 1994.

VAN DEN BERG, E.; OLIVEIRA-FILHO, A.T. Composição florística e estrutura fitossociológica de uma floresta ripária em Itutinga, MG, e comparação com outras áreas. Revista Brasileira de Botânica 23(3): 231-253. 2000.

VININHA, F. C. Ecoturismo e Preservação ambiental. Artigo publicado em 29/jul/2004. Jornalista e Diretora da Revista Ecotour. Internet, acesso em 10/ jul/2012.

WEBER, A. N. et al. Políticas Públicas em Biodiversidade: Conservação e uso Sustentado no País da Megadiversidade. Artigo Científico. 16/07/2009. 